\title{
LO MÍTICO Y SU RELACIÓN CON LO FANTÁSTICO EN LA OBRA DE J. L. BORGES*
}

Fecha de recepción: 13 de abril de 2013

Fecha de aprobación: 27 de abril de 2013

\section{Resumen}

En el presente trabajo intentaré dar una lectura del cuento borgeano "Las Ruinas Circulares" a partir de los planteamientos teóricos de Víctor Ivanovici desarrollados sobre lo fantástico, particularmente desde el componente mítico que el autor propone.

Con este objetivo, en un primer momento examinaré dos definiciones teóricas principales sobre esta categoría estética, vale decir, la de Tzvetan Todorov y la de Víctor Ivanovici. Posteriormente introduciré los elementos antropológicos que alimentan la propuesta ivanoviciana a través de autores como: Bronislaw Malinowski, Claude Levi-Strauss y Mircea Eliade. En un tercer momento contrastaré la definición teórica de Ivanovici, sustentado en los aportes antropológicos acerca del mito, con la lectura del cuento escogido, corroborando en él los elementos que propone el autor como esenciales para la categorización de lo fantástico.

Palabras clave: Borges, Ivanovici, Malinowski, Levi-Strauss, Eliade, mito, cultura, fantástico.

* El presente artículo se inscribe como producción dentro de la cátedra de "Problema de las Literaturas Hispánicas", dictado por la Dra. Cecilia Rubio Rubio en la Universidad de Concepción el primer semestre del año 2011.

\section{Iván Tapia Saavedra}

Universidad de Concepción, Chile

itapia@udec.cl

Psicólogo, licenciado en psicología y actualmente candidato a magíster en literaturas hispánicas por la Universidad de Concepción. Cuenta con la novela fantástica El cuarto de al lado (2013) en vías de publicación y otros artículos literarios. Participa en el grupo de investigación de literatura chilena de esta misma casa de estudios. Se desempeña actualmente como psicólogo en un centro de salud familiar y como investigador independiente. 


\title{
THE MYTHICAL AND ITS RELATION TO THE FANTASTIC IN THE WORK OF JORGE LUIS BORGES
}

\begin{abstract}
In this paper I will try to give a reading of the Borgean story "Las Ruinas Circulares" [The Circular Ruins], based on the theoretical approach of Victor Ivanovici regarding the category of the fantastic, particularly in what refers to the mythical component proposed by this author. With this intention, I will examine two different theoretical definitions of this aesthetic category: Tzvetan Todorov's and Victor Ivanovici's. Consequently, I will introduce the anthropological elements that feed the Ivanovician proposal through authors like: Bronislaw Malinowski, Claude Levi-Strauss and Mircea Eliade. Finally, I will contrast the Ivanovician theoretical definition -based on anthropological theory of myth- with a reading of the chosen short story, to corroborate the elements presented by Ivanovici as essential to the category of fantastic.
\end{abstract}

Key words: Ivanovici, Malinowski, Levi-Strauss, myth, culture, the fantastic.

\section{LE MYTHIQUE ET SON RAPPORT AVEC LE FANTASTIQUE DANS L'GEUVE DE J. L. BORGES}

\section{Résumé}

Dans ce travail j'essayerai de donner une lecture du conte borgésien «Les Ruines Circulaires » à partir des approches théoriques de Victor Ivanovici, développées sur le fantastique, en particulier à partir du composant mythique que l'auteur propose.

Avec cet objectif, tout d'abord ,j'examinerai deux définitions théoriques principales sur cette catégorie esthétique, c'est-à-dire, celle de Tzvetan Todorov et celle de Victor Ivanovici. Ensuite j'introduirai les éléments anthropologiques qui nourrissent le proposition d'Ivanovici à travers des auteurs comme : Bronislaw Malinowski, Claude Levi-Strauss et Mircea Eliade. Finalement je contrasterai la définition théorique d'Ivanovici, soutenu par les apports anthropologiques sur le mythe, avec la lecture du conte choisi, en y corroborant les éléments que l'auteur propose comme étant essentiels pour la catégorisation de ce qui est fantastique

Mots Clés: Borges, Ivanovici, Malinowski, Levi-Strauss, Eliade, mythe, culture, fantastique. 
"Yo no sé si bay algo explicable en el mundo, lo cual dudo" Jorge Luis Borges

\section{Introducción}

En una de las muchas entrevistas públicas que Jorge Luis Borges concedió a la prensa especializada en asuntos litera-rios, el autor señala, ante la pregunta del periodista Soler Serrano (1980), que no lograba entender el motivo por el cual su narrativa resultaba tan ampliamente leída: "yo no sé qué explicación puede haber, si es que hay algo explicable en el mundo, lo cual dudo", señaló. Estas palabras, además de corresponder a una extraordinaria muestra de sencillez, abren la posibilidad de que dentro del concepto borgeano de realidad no haya nada explicable o explicado y que todas las tentativas por comprender el funcionamiento de los fenómenos de la realidad no sean nada más que vanas ilusiones.

Según la RAE (2011), uno de los significados del verbo "explicar" es "llegar a comprender la razón de algo". A partir de ésto, si asumimos por un lado, como señala Borges, que no existe nada explicable en el mundo, y por otro, como señala Rubio (2008, p.10), que "tanto el arte como el ocultismo se presentan como dos modos análogos e idóneos de autoconocimiento y de conocimiento del mundo" nace entonces la posibilidad de concebir la producción artística borgeana como un intento de comprensión del mundo, vale decir, como un arte que va en búsqueda de la comprensión de los fenómenos.

Ahora bien, este arte cuyo objetivo sería la comprensión de la realidad, no tiene que ver con la intención de representar narrativamente una realidad objetiva "allá afuera", sino más bien con la construcción de normas propias, vinculadas a la disolución de las normas lógicas de ese mundo dado. Por tanto, según Ivanovici, en la creación borgeana existen ámbitos y personajes que de una u otra forma siguen manejándose de acuerdo a normas establecidas o previsibles pero que finalmente proponen una fuga respecto de tales normas (Ivanovici, 1999, p.41). Borges se sirve de tal fuga con respecto a lo establecido para proponer su mirada particular, la que tiene que ver principalmente con la llegada a lo fantástico. Risco (2000, p.163), señalará por su parte que:

de pronto, y sin ninguna verdadera preparación por su parte, cambia la naturaleza del contrato: el realista por el maravilloso. $Y$ es justamente el inesperado cambio de las condiciones del contrato de lectura lo que provoca la perplejidad del lector.

En relación al desarrollo de sus narraciones, no es menor señalar que la mayoría de los textos del autor argentino presentan un protagonista que se enfrenta a situaciones que escapan a su comprensión ( $\mathrm{La}$ Casa de Asterión, La Espera, etc.) y cuyas soluciones no se cobijan bajo una mentalidad propiamente realista. Por el contrario, la narrativa borgeana suele presentar una estética que puede quizá asemejarse a la realista pero que finalmente termina por evadir y sepultar bajo explicaciones existenciales, divinas, fantasmagóricas, algunas bordeando aspectos mitológicos y otras introduciéndose de lleno en ellos. Oscar Hahn señalará, de hecho, que "la edad de oro de la literatura fantástica hispanoamericana se inicia con la impresión de algunos cuentos de Borges en la revista Sur de Buenos Aires" (Hahn, 2001, p.90)

Uno de los autores principales dedicados a la problematización del concepto de lo fantástico es Víctor Ivanovici. En su texto El mundo de la nueva narrativa bispanoamericana (1999) define y problematiza los elementos que una categoría fantástica necesariamente debe considerar para ser reconocida como tal. A pesar de que el autor señala muchos aspectos, es posible notar que existe uno que es transversal al resto. Éste tiene que ver con el componente mítico, que es el elemento sobre el cual la narración fantástica debe construirse para ser considerada como una categoría estética particu- 
lar: "la raíz histórico cultural de lo fantástico, así como su fundamento estructural es el mito". (Ivanovici, 1999, p.19).

Ahora bien. Al ser Borges considerado un autor que se inscribe dentro del escenario fantástico, cabe la posibilidad de preguntarse de qué manera estos componentes míticos se actualizan en su producción artística y, a partir de ello, de qué manera la narrativa borgeana sirve u otorga una explicación y comprensión a los fenómenos del mundo.

En el presente artículo, por tanto, realizaré en un primer momento una revisión teórica sobre lo problemático que resulta una definición de lo fantástico, para luego proponer una lectura del cuento "Las Ruinas Circulares" a partir de la propuesta teórica definida por Víctor Ivanovici. Esta lectura, que enfatizará específicamente el componente mítico señalado por Ivanovici, intentará dar cuenta que efectivamente el cuento borgeano responde a un trasfondo mítico - religioso. Con este objetivo, me ayudaré de diversos autores que desde la antropología aportan conocimientos sobre el mito y el rol que cumple éste dentro del trasfondo cultural de un grupo humano.

\section{Lo fantástico}

Si bien es poco probable que alguien se atreva a cuestionar que el libro Introducción a la

Literatura Fantástica (2006) de Tzvetan Todorov -publicado originalmente en 1970marcó un antes y un después en la definición del concepto, en la actualidad es posible encontrar una multitud de definiciones sobre esta categoría estética, así como también una amplia variedad de temas que ésta aborda (Hahn, 1982, p.16). Hoy en día es posible encontrar numerosos textos que cuestionan la definición propuesta por el crítico francés, desechándola o actualizándola.

En su propuesta, Todorov señalará que existe un elemento fundamental que todo texto que se considere fantástico debe demostrar, y eso es, la ambigüedad entre dos soluciones posibles:

\begin{abstract}
Llegamos así al corazón de lo fantástico: en un mundo que es el nuestro se produce un acontecimiento que es imposible de explicar por las leyes de ese mismo mundo familiar. El que percibe el acontecimiento debe optar por dos soluciones posibles, o bien se trata de una solución de los sentidos y las leyes del mundo siguen siendo lo que son o bien el acontecimiento se produjo realmente, es parte integrante de la realidad y entonces esta realidad está regida por leyes que desconocemos... lo fantástico ocupa el lugar de esta incertidumbre. (Todorov, 2006, p.18)
\end{abstract}

De esta manera, el teórico francés divide el espectro narrativo en dos tipos de situa- ciones: los que dan pie para que esta ambigüedad se produzca y los que no. Aquellos textos que generan esta ambivalencia tendrán la posibilidad de ser considerados fantásticos si esta duda se mantiene hasta el final de la narración. Por el contrario, cuando esta duda es finalmente aclarada y el personaje opta por el camino racional como vía explicativa, dirá que lo fantástico deviene en "género extraño". Cuando, como otra manera de resolución, se acepta que existe ruptura de leyes naturales, Todorov dirá que nos encontramos en el "género maravilloso".

Muchas de las definiciones que hoy en día existen sobre lo fantástico rozan la propuesta de Todorov, particularmente en relación a aquel aspecto fundacional de quiebre de lo cotidiano a partir de un fenómeno no explicable desde las leyes que conocemos. Estas distintas concepciones del género, si bien parten desde la misma base, van haciendo diversos énfasis en las sensaciones o emociones producidas en el lector a partir de la lectura. Mientras que Todorov señala que la piedra angular en la definición de lo fantástico es la "duda" o la "vacilación", otros, como Roger Caillois o Howard Phillips Lovecraft enfatizarán aspectos como el miedo o el terror que la narración pueda generar en el lector. Como ejemplo de la propuesta todoroviana resulta paradigmático el caso del libro Dormir al 
sol (1973), del escritor argentino Adolfo Bioy Casares, en el que se narran las vivencias de un esposo cuya mujer ha sido internada en un hospital psiquiátrico. No es hasta casi el final de la lectura que tanto el narrador protagonista como el lector se plantean una explicación sobrenatural de los sucesos narrados: Samaniego, director del nosocomio, dice haber podido extraer el alma de un ser humano para curarla y que, a través del mismo procedimiento, ha extraído el alma de la esposa del narrador protagonista y la ha puesto en un perro que ha escapado del hospital. El narrador protagonista -con quien se identifica el lector-, en este caso, opta por adoptar como verídicas las explicaciones de Samaniego (es decir, disipa la duda, en términos de Todorov) y da forma a la novela como fantástica maravillosa, dado que se devela una explicación sobrenatural hasta entonces desconocida y que a partir de su conocimiento se asume como válida para los fenómenos hasta entonces incomprendidos.

Sobre la identificación del lector con el narrador, Todorov da especial énfasis a la necesidad de que el texto fantástico esté estructurado a través de un narrador en primera persona, argumentando a través de este mecanismo una mayor identificación entre el lector y el narrador. De esta forma, la idea es que "si el narrador en primera persona vacila $[\ldots]$ el lector también dude con respecto a lo que está viendo a través de los ojos de este narrador" (Ajuria, 2005, p.12). De esta forma $y$, siguiendo el ejemplo de la novela de Bioy Casares, la aceptación por parte del narrador protagonista de la explicación sobrenatural de Samaniego, da cabida para que el lector también la acepte y, por tanto, configure la novela como fantástica maravillosa.

De esta forma vemos cómo, desde Todorov, gran parte de la configuración fantástica del texto depende de un procedimiento desarrollado por el lector (identificación, vacilación, etc.) y no necesariamente por la "estructura" del texto mismo. Como he señalado, la mayoría de los teóricos que intentan definir los componentes que configuran un texto como fantástico, hace referencia, en su gran mayoría, a situaciones de esta naturaleza, vale decir, emocionales o racionales que aluden al lector (duda, certeza, terror, etc.) a partir de la narración de un fenómeno sobrenatural. Habrá, sin embargo, otros críticos que cuestionen este tipo de definiciones.

\section{La propuesta de Iva-} novici acerca de lo fantástico

Una de las críticas principales a la propuesta de Todorov las hará Víctor Ivanovici.
Ésta tiene que ver con lo que él califica como la "desaparición de lo fantástico". Para ello argumenta un hecho principal: Todorov crea un objeto fantástico que nace como un simple procedimiento de lectura, disuelto en una red de interrelaciones. Al hablar de procedimiento, Ivanovici se refiere justamente a lo anteriormente comentado, vale decir, a la duda que el lector debe resolver y que configurará finalmente el género del texto. Es decir, afirma Ivanovici, Todorov define un objeto fantástico que es evanescente y perecedero.

Ivanovici piensa que una definición de lo fantástico no puede estar constituida como un "simple procedimiento de lectura" y partir de componentes retóricos pues, de ser así, lo fantástico corre el riesgo de desaparecer. Por el contrario, esta definición debe necesariamente ajustarse a una categoría estética, estableciendo con ello, una zona de frontera sobre lo que debiera ser y lo que no debiera ser considerado como fantástico. De esta manera, señala Ivanovici, lo fantástico por fin puede ser situado debidamente, vale decir, como una categoría estética trascendente (que va más allá de la realidad) e histórica (existe un soporte cultural que la mantiene) a la vez:

Lo fantástico propicia y facilita la apertura del conocimiento artístico hacia un 
espacio ontológico de tipo trascendente en la acepción etimológica del término. En otras palabras, el contenido latente ${ }^{1}$ disfrazado en imágenes literarias o pictóricas de esta índole trasciende, esto es, pasa más allá del universo de la realidad, vale decir de las inercias y costumbres de nuestra vida y pensamiento, y abarca lo divino y demoníaco, lo irracional, el sueño, la locura, el éxtasis. (Ivanovici, 1999, p.18)

Resulta particularmente interesante el guiño que hace el autor al aparato psicoanalítico cuando define lo fantástico como "contenido latente disfrazado en imágenes literarias o pictóricas", pues con ello comienza a abrir el campo que introduce el elemento estructurante que definirá la categoría de lo fantástico: el mito.

Los mitos, por tanto, corresponderán a la narración de este contenido latente cultural que ha sido deformado por la cultura y configurado como manifiesto en la versión de creencias religiosas: "la génesis del texto fantástico topa una vez más con el mito, cuyas estructuras informan el inconsciente colectivo." (Ivanovici, 1999, p.26). O como señala Lovecraft en Ivanovici (1999, p.25):

Esta emoción implica un molde psicológico y una tradición arraigada en la experiencia mental... la inevitable emoción de lo maravilloso nace de un complejo cuerpo de agudas emociones y de provocación imaginativa cuya vitalidad ha de ser necesariamente tan permanente como la raza humana.

Lo que Lovecraft sospechó y reconoció como "tradición arraigada en la experiencia mental tan permanente como la raza humana", es lo que Ivanovici señala luego como inconsciente colectivo, al referirse a las creencias culturales compartidas. Posteriormente, investigadores desde la antropología abordarán estas creencias compartidas y propondrán el elemento que Ivanovici aborda (el mito) como el elemento central estructurador del pensamiento humano. El autor lo gráfica de tal manera en el siguiente esquema:

\section{Cultura $\rightarrow$ representacio- nes religiosas configuradas por ella $\rightarrow$ mitos y folklore como fuente $\rightarrow$ procesa- miento literario fantástico.}

\section{Lo mítico}

Ivanovici señalará en su texto que uno de los aspectos fundamentales de la literatura fantástica corresponde al elemento mítico religioso que le da sustento. Para ello se basa en los estudios de Vladimir Propp, teórico literario ruso que influyó en los posteriores conocimientos de Claude LeviStrauss, principal exponente de lo mítico desde la antropología estructuralista. Tanto LeviStrauss (2002), desde lo antropológico, como Ivanovici (1999), desde lo literario, inician sus formulaciones teóricas desde un punto de vista histórico cultural que propone lo mítico como patrones explicativos compartidos por distintas culturas. El objetivo de estas narraciones tendría que ver principalmente con la formulación de diversas explicaciones que un grupo humano crea para comprender situaciones de índole trascendental y/o religiosa: de dónde venimos, a dónde vamos, razón de existir, etc. Estas narraciones, como afirmarán también otros teóricos "no son solamente historias contadas, sino que realidades vivientes" que configuran la experiencia cotidiana de los sujetos (Malinowski, 1948, p.100). Estas explicaciones no son de tipo racional sino de orden cultural.

Según el rumano Mircea Eliade, resulta en extremo

1 Cuando hablamos de "contenido latente disfrazado en imágenes pictóricas" nos estamos refiriendo, finalmente, al mecanismo del sueño postulado por el psicoanálisis. En éste, existe un contenido inconsciente que no es capaz de acceder a la consciencia sino a través de algún disfraz que permita este procedimiento. Llamaremos contenido latente a las causas inconscientes, mientras que entenderemos como contenido manifiesto a la deformación de estos elementos que devienen en el sueño mismo. Esta aclaración es importante pues Ivanovici postula en su definición, a través de este mismo sistema, los mecanismos sobre los que se funda la categoría de lo fantástico. 
difícil elaborar una definición que sea capaz de abarcar todas las dimensiones del mito. Señala, sin embargo, algunas características que configuran este tipo de narraciones en las sociedades primitivas y tradicionales:

\begin{abstract}
el mito cuenta una historia sagrada, relata un acontecimiento que ha tenido lugar en un tiempo primordial, el tiempo fabuloso de los «comienzos» $[. .$.$] el mito cuen-$ ta cómo, gracias a las hazañas de los Seres Sobrenaturales, una realidad ha venido a la existencia, sea ésta la realidad total, el Cosmos, o solamente un fragmento: una isla, una especie vegetal, un comportamiento humano, una institución (Eliade, 2010, pp.13-14).
\end{abstract}

De esta forma, la narración mítica no habla de lo que ha sucedido realmente en un momento determinado de la historia, sino que relata el tiempo de los "comienzos" imaginarios, hechos supuestos de un acontecimiento inaugural tomados por verdad. Este momento "mítico-creacional", por una parte establece las creencias de lo que somos hoy en día como personas insertas socialmente y, por otra, señala la separación entre lo profano y lo divino. Esta separación entre sagrado - mundano, resulta vital para la comprensión de estas narraciones en tanto el mito es considerado una "historia verdadera" y por tanto sagrada. En este sentido, señala Eliade, el mito entrega un marco crítico que establece, entre otras cosas, lo que la comunidad considerará como bueno o malo, como permitido o como prohibido.

Ante la pregunta antropológica de por qué ciertas conductas existen en determinadas sociedades, surgen respuestas que nos remite por lo general a una causalidad mítica primaria, que estableció que ciertas acciones eran benéficas y otras no. De ahí el vínculo tan importante que existe entre mito y religiosidad, el primero de ellos concebido como narración maravillosa y el segundo como un sistema de creencias acerca de la divinidad. Las diversas religiosidades, entonces, como sistema de creencias, se encuentran íntimamente imbricadas con las mitologías y establecen polos como lo sagrado y lo profano, lo verdadero y lo falso, lo bueno y lo malo: "por el mismo hecho de relatar el mito las gestas de los seres sobrenaturales y la manifestación de sus poderes sagrados, se convierte en el modelo ejemplar de todas las actividades humanas significativas" (Eliade, 2010, p.14). Robert Redfield en el prólogo de Magic, Science and Religion and Other Essays (Malinowski, 1948, p.10), señala:

la religión no consiste solamente en personas que explican y proyectan sus sueños, no es tampoco únicamente una herramienta para mantener una comunión social, no; la religión y la magia son las vías que los hombres tienen, por ser hombres, para hacer el mundo tolerable, manejable $\mathrm{y}$ adecuado.

Es decir, lo religioso, comprendido como un sistema de creencias sobre las divinidades, funcionaría como un eslabón dentro de la cadena explicativa del orden de nuestras sociedades y las causas de su existencia.

Levi-Strauss será otro de los teóricos que aborde la estructura del mito, coincidiendo con Eliade en que éstos separan la conciencia humana en dos polos, uno propositivo y otro negativo. Así, si existe Dios, existe también Satanás, si existe vida, existe también muerte, etc. Como vemos, el componente fundacional se encuentra presente en todo momento dentro de la estructura de los mitos.

\section{Lo mítico en "Las Ruinas Circulares"}

Según Víctor Ivanovici, como se ha dicho, el fundamento estructural de toda narración fantástica es el mito. Señala que es gracias a él que lo fantástico puede establecerse como una categoría estética imperecedera y trascendente, refutando de esta manera, los "procedimientos de lectura" establecidos por Todorov y otros teóricos. Lo fantástico entonces sería el "procesamiento literario" de los mitos $y$ el folklore presente en una 
cultura particular. De esta forma, el texto narrativo fantástico podría ser leído como un reflejo, o una deformación (en el sentido de contenido manifiesto) de un contenido latente conformado por mitología y folklore.

En este sentido, el vínculo que existe entre la literatura borgeana y los elementos anteriormente presentados resulta innegable. Borges es un asiduo trabajador de elementos metafísicos y religiosos que dan pie a muchas de sus narraciones, constituyéndose éstas en directa relación con elementos míticos culturales. Una de las obras en que es posible apreciar de mejor manera esta situación es el cuento "Las Ruinas Circulares" (Borges, 1997).

En este texto, el narrador presenta un hombre que intenta crear a otro, para lo cual debe dirigirse a un lugar físico propicio que permita tal esfuerzo y concentración. Después de muchas peripecias logra finalmente ubicar el ambiente adecuado para dedicarse al propósito que lo convoca: soñar. Será a través del sueño que su obra nazca a la realidad, la que se constituirá como un hombre que tendrá la garantía de que el fuego no lo devorará ni le hará daño, a diferencia del resto de los mortales. Luego de nacido y después de un largo proceso de instrucción, lo envía a una aldea lejana para que pueda ahí vivir.
Estando el creador nuevamente solo, de pronto ve que las ruinas circulares que otrora le dieron cobijo y que permitieron que su creación de hombre fuera posible, comienzan a incendiarse. Envueltos en potentes llamaradas, los grandes pilares comienzan a llegar a su fin, provocando en el anciano las innatas ganas de protegerse e intentar huir. Sin embargo, se frena ante esta reacción, pues comprende que su hora de morir ha llegado. Asumido el destino, camina con solemnidad hasta las lenguas de fuego para descubrir que no le hacían daño, dándose cuenta, de esta forma, "con alivio, con humillación, con terror que él también era una apariencia que otro estaba soñando".

En un comentario que el propio Ivanovici hace de Borges, señala que el mito en la narrativa borgeana viene a ocupar un lugar conservador, enfatizando "el modo en que la estructura literaria fantástica [borgeana] se remite al fondo mítico-arquetípico de nuestra categoría" (Ivanovici, 1999, p.40). De tal forma, el autor corrobora lo que se ha venido señalando en estas páginas, vale decir, la estrecha relación que existe entre los escritos borgeanos y lo que Eliade denomina como mitos cosmogónicos, vale decir, aquellos mitos arquetípicos que re-crean el origen del cosmos y de todas las cosas, presentes en todas las culturas: "la cosmogonía constituye el mode- lo ejemplar de toda situación creadora; todo lo que hace el hombre, repite en cierta manera el "hecho" por excelencia, el gesto arquetípico del Dios creador: la Creación del Mundo" (Eliade, 2010, p.38). Al tomar en cuenta los planteamientos que Malinowski hace acerca de los mitos y su relación con la religión y la magia, es posible mostrar los elementos míticos que sostienen el cuento "Las Ruinas Circulares". Malinowski (1948, pp.87-88) señala que

\begin{abstract}
tanto la magia como la religión están basados estrictamente en tradición mitológica y ambos existen dentro de la atmósfera de lo milagroso, en una constante revelación de sus poderes mágicos. Ambos están rodeados de tabús y observancias que separan sus actos de los del mundo profano.
\end{abstract}

Este aspecto resulta fundamental desde el comienzo del cuento, en que el narrador señala:

El propósito que lo guiaba no era imposible, aunque sí sobrenatural. Quería soñar un hombre: quería soñarlo con integridad minuciosa e imponerlo a la realidad [...]. Le convenía el templo inhabitado y despedazado, porque era un mínimo de mundo visible; la cercanía de los labradores también, porque éstos se encargaban de subvenir a sus necesidades frugales. El arroz y las frutas de su tributo eran pábulo suficiente para su cuerpo, consagrado a la única tarea de dormir y soñar (Borges, 1997, pp.57-58). 
Hay tres elementos dentro de este párrafo que permiten observar uno de los aspectos constituyentes de todo mito; me refiero a aquella división en dos polos opuestos que configuran generalmente las narraciones míticas y religiosas.

El primer elemento hace referencia a la ofrenda religiosa. El protagonista de la historia siente la conveniencia de tener a los labradores cerca suyo, pues éstos le contribuían con alimentos, permitiéndole sólo abocarse a su labor de soñador: "el arroz y las frutas de su tributo...". Luego de leer aquel párrafo, una de las interrogantes que muy posiblemente surja en los lectores es acerca del motivo por el cual los hombres regalaban a este ser sus alimentos. Esta pregunta es válida en tanto que el texto no menciona interacción alguna entre estos habitantes y este hombre - creador que justifique tal dádiva. Pues bien, dadas las características del ser a quien se le regalaban los alimentos, se determina que tal regalo correspondía a una ofrenda. Es este elemento la ofrenda religiosa, la que genera desde un comienzo de la historia la división entre los que ofrendan y aquel que es ofrendado, de manera tal que este tributo delimitará los terrenos que les corresponde ocupar a cada uno: el polo divino a este ser creador, por un lado, y el terrenal a los hombres que ofrendan, por el otro.

La ofrenda constituye uno de los elementos principales en la mayoría de los credos religiosos en las distintas culturas. Freud expone en su texto Tótem y Tabú (2000) - publicado inicialmente en el año 1913- la manera en que las ofrendas hechas a la divinidad perseguían el objetivo de aplacarla o de conseguir algún tipo de favor: "solicitaban su amparo y temían su magia".

De esta manera, lo mítico del texto nos orienta hacia una esfera más bien religiosa en que la ofrenda cumple el rol de objeto de cambio: cobijo y ayuda a cambio de alimentos ofrendados.

El segundo aspecto que es posible reconocer en el párrafo y que tiene relación con uno de los enunciados de Levi-Strauss acerca de lo mítico, tiene que ver con una de las palabras utilizadas por el autor: consagrado. El narrador la utiliza para expresar la única actividad a la que el protagonista del cuento se aboca, dándole un cariz de divinidad: "consagrado a la única tarea de dormir y soñar". Es esta palabra la que nos remite a las definiciones presentadas anteriormente con respecto a lo mítico según Levi-Strauss: (consagrado), la que en su raíz (sagrado), nos orienta a aquel rasgo de los mitos en que existe una división que separa, por un lado lo que es digno de veneración por su carácter divino o por estar relacionado con la divinidad (RAE, 2011) y por el otro, lo terreno. De esta manera, las actividades del hombre - creador se diferencian del resto de los hombres justamente porque está consagrado a ella, vale decir, ha hecho sagrada su actividad de dormir y soñar.

El tercer aspecto que muestra la presencia de componentes míticos en el cuento de Borges, es, nuevamente, la separación de dos polos, producida esta vez entre cuerpo y alma. Cuando el narrador señala que los alimentos traídos para el protagonista eran suficientes para su cuerpo: "pábulo suficiente para su cuerpo", una de las interpretaciones posibles es señalar que el narrador intenta lograr la separación entre lo humano, lo carnal, lo mortal, lo perecedero por un lado (todo aquello que requiere alimento físico para mantenerse con vida) y lo divino, espiritual y trascendental, por otro. Visto desde este aspecto, el alimento es "alimento para el cuerpo", como señala textualmente la historia, sólo cuando se intenta diferenciar el elemento carnal de otros elementos, como el alma. De esta manera, el alimento deja de serlo para mí o para él, visto el "yo" o "él" como un ser unificado, y pasa a ser un alimento para mi cuerpo o el suyo. Así, el que recibe los alimentos terrenales, en este sentido, es el cuerpo, pues el alma de este hombre - creador ha de alimentarse de otro elemento distinto: el sueño. Es por este motivo que algunos párrafos 
más adelante el protagonista de la historia se muestra tan perturbado por la imposibilidad de conciliar el sueño, pues es finalmente un alma que deja de recibir la materia prima que la mantiene viva.

Otro de los aspectos constitutivos de los mitos es su repetida alusión a lo cosmogónico. De esta manera, como señala Ivanovici, no parece extraño que el contenido primordial de las distintas mitologías dé cabida a lo religioso, pues es éste el sistema de creencias que ordena y da sentido a todo cuanto tenga que ver con las divinidades y por tanto, con lo creacional. En este sentido, el cuento "Las Ruinas Circulares", por tratarse de un hombre que busca dar origen (crear) a otro hombre: "quería soñar un hombre: quería soñarlo con integridad minuciosa e imponerlo a la realidad" (Borges, 1997, p.57), hace referencia directamente al aspecto mítico religioso creacional, situación que es leída por Ivanovici como "fantasía conservadora" por la alusión a lo arquetípico de los mitos.

Al preguntamos acerca de la pertinencia de este calificativo (conservador) por parte del teórico, es posible señalar que efectivamente en el cuento se visibiliza una estrategia narrativa que es utilizada por la mayoría de los credos (los tres grandes de occidente: cristianismo, judaísmo, islam) y que tiene que ver con aquel aspecto conservador. En estas historias religio- sas existen diversas lecturas del mito cosmogónico que guardan de cierta forma alguna similitud: generalmente existe un padre que crea a un hijo y que envía como emisario de su mensaje. En el caso del cristianismo será un mesías mientras que en el caso del islam y el judaísmo será un profeta (Mahoma y Abraham). En el caso del cuento borgeano será un hijo que comparte las características de profeta y mesías: "le ordenó que una vez instruido en los ritos, lo enviara al otro templo despedazado cuyas pirámides persisten aguas abajo, para que alguna vez lo glorificaran en aquel edificio desierto". En este párrafo incluso puede leerse una historia similar a la del cristianismo en que el creador es Dios ("le ordenó"), el enviado es Jesús ("lo enviará"), el "otro templo despedazado" es el mundo dañado por el pecado y la especie humana como aquellos que "glorificaran en el edificio desierto".

Si se repite una estructura similar en estas tres religiones y el cuento es porque el mito entrega al pensamiento humano diversos elementos comunes que, sin importar la cultura, posibilitarán el posterior tratamiento literario y el surgimiento de creaciones propiamente fantásticas. Ahora bien, ¿por qué es necesario señalar ésto?, pues porque esta es la misma estructura que sigue el cuento borgeano, de tal manera que incluso podría verse en él según desde dónde observamos- una narración religiosa o una narración fantástica. Muy probablemente si el cuento fuera leído al interior de alguna ceremonia religiosa y los oyentes no supieran que efectivamente se trata de un cuento fantástico, sería reconocido como una narración religiosa por parte de los oyentes.

Ahora bien, retomando lo que inicialmente había planteado Levi-Strauss como elemento característico de los mitos, es posible encontrar que junto a la creación o construcción, se encuentra por lo general un elemento que destruye. De esta manera, existe el demonio porque existe Dios, existe el bien porque existe el mal, existe la creación, porque también existe la destrucción. Es en este sentido que el cuento analizado ofrece también tal elemento, o más bien dicho, ofrece su posibilidad. Como se señaló en el resumen de la historia, este hombre - creador, al ver que su fin se acercaba y que sería pronto víctima del templo cayéndole encima, se dirigió a las llamas que devoraban el edificio sin que éstas le hicieran daño: "Caminó contra los jirones de fuego. Estos no mordieron su carne, éstos lo acariciaron y lo inundaron sin calor y sin combustión. Con alivio, con humillación, con terror, comprendió que él también era una apariencia, que otro estaba soñándolo" (Borges, 1997, p.57).

Otro de los aspectos que a mi juicio resulta muy relevante mencionar, tiene que ver con 
lo que puede leerse como un intento de reconstrucción de la práctica religiosa, ensayado por Borges en su narración, lo que en realidad da cuenta del aspecto cosmogónico del mito. Esto queda patente cuando el narrador señala que los hombres comienzan a dirigirse nuevamente a un lugar de culto que ha sido antes abandonado, con el fin de rendir tributo:

\begin{abstract}
el recinto circular que corona un tigre o caballo de piedra, que tuvo alguna vez el color del fuego y ahora el de la ceniza (...) ese redondel es un templo que devoraron los incendios antiguos, que la selva palúdica ha profanado y cuyo dios no recibe el honor de los hombres (...) sabía que los árboles incesantes no habían logrado estrangular, río abajo, las ruinas de otro templo propicio, también de dioses incendiados y muertos... (Borges, 1997, pp.56-57)
\end{abstract}

En este párrafo se recurre a una estrategia para generar un contraste entre lo que alguna vez fue este lugar sagrado y lo que es en el presente. Con este objetivo el narrador utiliza el color del templo: "color del fuego" y "ahora el de la ceniza", haciendo una analogía entre lo activo (fuego) y lo no activo (ceniza). Recordemos nuevamente que bien estudiado resulta el vínculo entre el cristianismo y el totemismo para Freud, en que el fuego ocupa un lugar preponderante como agente de cambio, como algo vivo, mientras que las cenizas ocupan el lugar de lo ya no vivo: "del polvo vienes y en polvo te convertirás".

Luego de hacer esta diferencia entre lo que el templo fue y lo que es ahora, el narrador señala que estos hombres cercanos espiaban su sueño y se aproximaban ante un ser que reconocían como superior: "rastros de pies descalzos, unos higos y un cántaro le advirtieron que los hombres de la región habían espiado con respeto su sueño (Borges, 1997, p.57).", logrando actualizar en un presente narrativo la puesta en marcha de nueva actividad religiosa por parte de los habitantes de la región.

\section{Conclusiones}

Luego de haber revisado, desde una mirada propuesta por Ivanovici, los componentes principales del cuento borgeano, queda, sin embargo, la necesidad de generar algunas reflexiones en torno a la concepción de lo fantástico y su relación con lo mítico en el cuento estudiado.

Al momento de asumir como certeros los hallazgos antropológicos presentados, estoy al fin y al cabo reconociendo que la utilidad de los mitos radicaba y radica en la posibilidad de otorgar un orden y un sentido a la experiencia, particularmente aquella cotidiana. De la misma manera, si reconozco -luego de haberlo corroborado en el presente trabajo-, que los planteamientos de Ivanovici son co- rrectos, es decir, que la narrativa fantástica emerge a partir de los terrenos de lo mítico como un contenido manifiesto de aspectos culturales, entonces asumo que mi idea principal planteada en la introducción es acertada. Ésta, en tanto lo fantástico, particularmente lo borgeano, tendría una intención explicativa acerca de acontecimientos primordiales (la vida, la muerte, dios, hombres, etc.). Es decir, si la base utilizada para nutrir la creación fantástica borgeana es una base mítica conservadora, es posible llegar a la conclusión de que lo fantástico en Borges entonces tendría una intención comprensiva y explicativa de la realidad. Esto, más aún, al reconocer el propio autor que para él no existe nada explicado en el mundo.

Ivanovici califica a Borges en sus textos como un fantástico conservador justamente porque el autor argentino basa su prosa, particularmente en este cuento, en una serie de mecanismos que terminan remitiéndonos o reflejando un trasfondo clásicamente arquetípico, en relación a la Creación. El objetivo de este texto ha sido comprobar aquel enunciado a través del análisis de un cuento, señalando que la proposición ivanoviciana es correcta. Es este trasfondo el que le permite al autor crear textos fantásticos, vinculándolos por lo general a las grandes preguntas existenciales que giran en las conciencias de los hombres y que, por cierto, dan origen a disciplinas como la filosofía o la religión. 


\section{Referencias}

Ajuria, E. (2005). "Fantasía y compromiso social en los relatos de Juan Rulfo y de Julio Cortázar". Tesis de licenciatura en literatura, Universidad de las Américas Puebla. Escuela de Artes y Humanidades, Departamento de Filosofía y Letras. Disponible en: http://catarina.udlap.mx/u_dl_a/tales/documentos/ lli/ajuria_i_e/portada.html

Borges, J. (2005). El Aleph. Buenos Aires: Emecé.

Borges, J. (1997). Ficciones. Madrid: Alianza.

Eliade, M. (2010). Mito y realidad. Barcelona: Kairós.

Freud, S. (2000). Tótem y Tabú. Madrid: Alianza.

Hahn, O. (1982). El cuento fantástico hispanoamericano en el siglo XIX. Estudios y textos. México: Premia Editora.

Hahn, O. (2001). Magias de la escritura. Santiago: Andrés Bello.

Levi-Strauss, C. (2002). Mito y significado. Madrid: Alianza.

Malinowski, B. (1948). Magic, Science and Religion and Other Essays. Nueva York: Doubleday Anchor Books.

Real Academia Española. (2011, junio 14) Diccionario en línea. [on line]. Disponible en: www.rae.es

Risco, A. (2000). Lo fantástico en "Las ruinas circulares". Escritos. Revista del Centro de Ciencias del Lenguaje. $21,155-177$.

Rubio, C. (2008). La euritmia de Juan Emar: teoría del equilibrio y sistema constructivo. Acta Literaria. 37, $9-23$.

Soler, J. (1980) Jorge Luis Borges - Entrevista Soler Serrano 1980 1/9. En YouTube [on line]. Disponible en: www.youtube.com/watch?v=7ER919AtOgA.

Ivanovici. V. (1999) El mundo de la nueva narrativa hispanoamericana. Quito: Casa de la Cultura Ecuatoriana.

Todorov, T. (2006). Introducción a la Literatura Fantástica. Buenos Aires: Paidós. Disponible en línea en: http://www.catedu.es/IESLiteratura/lectura/cuarto_atras/imagenes/Todorov.pdf 